\title{
Medial tunica degeneration of the ascending aortic wall is associated with specific microRNA changes in bicuspid aortic valve disease
}

\author{
CALOGERA PISANO $^{1^{*}}$, ANTONELLA MARINO GAMMAZZA ${ }^{2 *}$, FRANCESCA RAPPA $^{2 *}$, ROSARIO BARONE $^{2}$, \\ ROSALINDA ALLEGRO ${ }^{3}$, ALESSANDRO PITRUZZELLA $^{2}$, ALESSANDRA TAGLIAVIA $^{4}$, VIRGINIA AGOSTARA $^{4}$, \\ GIOVANNI RUVOLO ${ }^{1}$, FRANCESCO CAPPELLO ${ }^{1}$ and VINCENZO ARGANO ${ }^{4}$ \\ ${ }^{1}$ Cardiac Surgery Unit, Tor Vergata University Hospital, I-00133 Rome; Departments of ${ }^{2}$ Biomedicine, \\ Neurosciences and Advanced Diagnostics, ${ }^{3}$ Statistics and ${ }^{4}$ Cardiac Surgery, University of Palermo, I-90100 Palermo, Italy
}

Received October 11, 2020; Accepted July 6, 2021

DOI: $10.3892 / \mathrm{mmr} .2021 .12516$

\begin{abstract}
Ascending aortic diameter is not an accurate parameter for surgical indication in patients with bicuspid aortic valve (BAV). Thus, the present study aimed to identify specific microRNAs (miRNAs/miRs) and their expression levels in aortic wall aneurysm associated with BAV according to severity of medial degeneration and to elucidate the association between the tissue expression levels of the miRNAs with their expression in plasma. Aortic wall and blood specimens were obtained from 38 patients: 12 controls and 26 patients with BAV with ascending aortic aneurysm. Of the patients with BAV, 19 had cusp fusions of right and left, 5 of right and non-coronary, and 2 of left and non-coronary. Two groups of patients were identified according to the grade of medial degeneration (MD): Low-grade D group (LGMD) and high-grade MD group (HGMD). Expression level of miR-122, miR-130, miR-718 and miR-486 were validated by reverse transcription-quantitative PCR in plasma and tissue samples. MD grade was found to be independent from the BAV phenotype. The HGD group showed increased expression levels of MMP-9 and MMP-2, and an increase in the number of apoptotic cells. Tissue expression levels of miR-718 and miR-122 were lower in the LGMD and HGD groups compared with expression in the control group; the HGD group showed increased levels of miR-486. Plasma expression levels of miR-122 were decreased in the LGMD and HGD groups, and miR-718 was only reduced in the HGD group. On the contrary, expression of miR-486 was
\end{abstract}

Correspondence to: Professor Calogera Pisano, Cardiac Surgery Unit, Tor Vergata University Hospital, 81 Viale Oxford, I-00133 Rome, Italy

E-mail: lindapisano82@gmail.com

*Contributed equally

Key words: bicuspid aortic valve disease, microRNAs, ascending aorta, biomarkers increased in the LGMD and HGD groups. The data suggested that miR-486 may be considered as a non-invasive biomarker of aortic wall degeneration. Dysregulation of this putative biomarker may be associated with high risk of dissection and rupture in patients with BAV.

\section{Introduction}

Bicuspid aortic valve disease (BAV) represents the most common congenital heart defect. BAV is generally considered to affect 0.5 to $1.4 \%$ of the population, with a male prevalence based on autopsy studies and small echocardiographic studies (1-3). BAV is a complex and heterogeneous disease accounting for more premature deaths than all other congenital heart diseases combined (4). The mechanism of the disease process is still unclear, and a number of questions remain unanswered. BAV can occur as a component of genetic syndromes. For example, $30 \%$ of women with Turner syndrome also have BAV (5). On the other hand, evidence of familial clustering of BAV suggests that familial inherited BAV aligns with autosomal dominant transmission with reduced penetrance (6). Analysis of particular pedigrees, positional cloning approach, and genetic analysis have proven to be crucial to the discovery of multiple genetic loci associated with familial BAV, including the involvement of the Notch1 and GATA binding protein 5 (7,8) Different phenotypes of BAV have been identified according to cusp fusion (9): i) Phenotype I, right-left (R-L) coronary cusp fusion, which is associated with coarctation of the aorta, aortic stenosis and increased aortic wall shear stress; ii) phenotype II, right-non-coronary (R-NC) cusp fusion, associated with cusp pathology, aortic stenosis and regurgitation, aortic aneurysm, larger aortic arch dimensions and myxomatous mitral valve disease; and iii) phenotype III, left-non-coronary (L-NC) cusp fusion, which is rare.

The most common abnormality in adults with BAV is enlargement of the thoracic aorta (10) and this varies according to the pattern of cusp fusion, with faster rates of aortic sinus and ascending aortic dilatation associated with the L-R compared with the R-NC morphology. 
In the present study, morphological evaluations of the ascending aortic wall from patients with BAV were performed. This analysis was focused on elucidating the association between the alterations in the expression levels of the selected microRNAs (miRNAs/miRs) in tissues and recirculating blood through a biomolecular analyses. This work may provide groundwork for the possible identification of novel and usable biomarkers focused on rupture and dissection, which are hallmarks of severity and clinical complications in BAV.

\section{Materials and methods}

Clinical data. This study was approved by the Institutional Review Board of University of Palermo (Palermo, Italy; approval no. CE 2A17-000-527-28). Written informed consent was obtained from all participants. The present study included patients with BAV with aneurysm (17 men and 9 women; age, 59.2 \pm 17.3 years) admitted between January 2014 and January 2015 to the Cardiac Surgery Unit at the University of Palermo for surgical procedures. According to the morphology of BAV, $73 \%$ (19 cases) presented the R-L BAV phenotype, $19 \%$ ( 5 cases) presented the R-NC phenotype and $8 \%$ (2 cases) presented the L-NC phenotype (Table I and Fig. S1). Evaluation of the BAV morphology and ascending aorta diameter was performed preoperatively and in the operating room by transthoracic echocardiography and transesophageal echocardiography. Furthermore, measurements of aortic root and ascending aortic diameter sizes were carried out using helical computed tomography image analysis techniques. The mean diameter of the aortic root was $48.5 \pm 1.8 \mathrm{~mm}$, the mean diameter of the ascending aorta was $54.03 \pm 1.5 \mathrm{~mm}$. Relevant medical histories regarding aortic disease were obtained from the patients' medical records (Table I). The surgical procedure used was The Button Bentall Procedure (11). Control ascending aortic specimens were obtained from 12 patients ( 8 men, 4 women; age, $53.2 \pm 16.5$ years) with tricuspid aortic valve not associated to aortopathy underwent cardiac surgery for coronary artery diseases. This surgical action allowed us to obtain a sample of the aortic wall from subjects who had no clinical damage to the aorta. The control cases had no history of smoking, hypertension or diabetes.

Aortic specimens and histopathological evaluation. Aortic specimens were collected from the resected walls of the ascending aorta of both BAV and control patients at the time of surgery and embedded in paraffin. The samples were fixed in $10 \%$ buffered formalin for $24 \mathrm{~h}$ at room temperature and embedded in paraffin. Sections $(5 \mu \mathrm{m})$ were obtained from paraffin blocks of samples with a cutting microtome. The sections were stained with H\&E or Alcian periodic acid-Schiff (PAS), as described previously (12). Masson's Trichrome staining using a Masson's Tricromica kit (cat. no. 04-010802; Bio Optica Milano SpA) and Weigert Van Gieson staining using an Elastic Stain kit (cat. no. HT25A-1KT; Sigma-Aldrich; Merck KGaA) were also conducted. Following staining, the slides were observed with an optical microscope (Leica DM 5000 B Microscope; Leica Microsystems, Inc.) connected to a digital camera (Leica DC300 F; Leica Microsystems, Inc.). H\&E staining was performed for medionecrosis evaluation, Alcian PAS stain was performed for the evaluation of PAS-positive mucoid material accumulation, Masson's Trichrome stain was performed for fibrosis evaluation, and Elastic Stain was performed for the identification of elastic fibers alterations. The histological evaluation of the ascending aortic wall was performed according to criteria adapted from Schlatmann and Becker (13) and de Sa et al (14); the histological data were analyzed in a semi-quantitative manner. Each alteration was graded from 0 (no change) to 3 (severe change). For each patient, the sum of the values measured was calculated as the aortic wall score. For the histological evaluation, all specimens were evaluated independently by two observers (FR and FC), who were blinded to the clinical data $(13,14)$.

Immunohistochemistry. Immunohistochemical experiments were performed on 4-5 $\mu$ m thick $10 \%$ buffered formalin fixed and paraffin-embedded sections of the ascending aortic wall, obtained from paraffin blocks with a cutting microtome as previously described $(15,16)$. All sections were dewaxed in xylene for $30 \mathrm{~min}$ at $60^{\circ} \mathrm{C}$ and rehydrated, at room temperature, by sequential immersion in a graded series of alcohols and transferred into water for $5 \mathrm{~min}$. Subsequently, the sections were immersed for $8 \mathrm{~min}$ in sodium citrate buffer ( $\mathrm{pH}$ 6.0) at $95^{\circ} \mathrm{C}$ for antigen retrieval and subsequently in Aceton at $-20^{\circ} \mathrm{C}$ for $8 \mathrm{~min}$ to prevent the detachment of the sections from the slide. All subsequent reactions were conducted at room temperature. After washing with PBS ( $\mathrm{pH}$ 7.4) for $5 \mathrm{~min}$, the sections were treated for 5 min with Peroxidase Quenching Solution (reagent A of Histostain ${ }^{\circledR}$-Plus 3rd Gen IHC Detection Kit; Invitrogen; Thermo Fisher Scientific, Inc.) to inhibit any endogenous peroxidase activity. After washing with PBS for $5 \mathrm{~min}$, the sections were treated with a blocking protein (reagent B of Histostain ${ }^{\circledR}$-Plus 3rd Gen IHC Detection Kit) for 10 min to block non-specific antigenic sites. Subsequently, the sections were incubated with the following primary antibodies overnight at $4^{\circ} \mathrm{C}$ : Anti-MMP9 (mouse monoclonal antibody; 1:100; cat. no. sc-21733; Santa Cruz Biotechnology, Inc.) and anti-MMP2 (mouse monoclonal antibody; 1:100; cat. no. sc-53630; Santa Cruz Biotechnology, Inc.). Appropriate positive and negative (isotype) controls were run concurrently. Following washing with PBS for $5 \mathrm{~min}$, the sections were incubated with a universal biotinylated secondary antibody (Biotinylated Secondary Antibody Reagent C from Histostain ${ }^{\circledR}$-Plus 3rd Gen IHC Detection Kit) for $10 \mathrm{~min}$. After a subsequent washing with PBS for $5 \mathrm{~min}$, the sections were incubated with streptavidin-peroxidase complex (Streptavidin-Peroxidase Conjugate Reagent D Histostain ${ }^{\circledR}$-Plus 3rd Gen IHC Detection Kit) for $10 \mathrm{~min}$, and following a further washing in PBS for $5 \mathrm{~min}$, the slides were incubated in the dark for 5 min with the DAB chromogen reagents E1 and E2 (Histostain ${ }^{\circledR}$-Plus 3rd Gen IHC Detection Kit). Nuclear counterstaining was carried out using hematoxylin (Hematoxylin aqueous formula; cat. no. S2020; Bio Optica Milano SpA). The specimens were examined by two independent observers (FR and FC) that performed a quantitative evaluation to determine the percentage of smooth muscle cells of the medial tunica. The percentage of immunopositivestained cells was then calculated in a high-power field (magnification, $\mathrm{x} 400$ ) and repeated for 10 fields; the arithmetic means of counts were used for statistical analyses. 
Table I. Clinicopathological characteristics of the study population.

\begin{tabular}{|c|c|c|c|}
\hline \multirow[b]{2}{*}{ Clinicopathological characteristic } & \multicolumn{2}{|c|}{ Group } & \multirow[b]{2}{*}{ P-value } \\
\hline & L-NC and R-NC $(n=7)$ & R-L (n=19) & \\
\hline Age, mean \pm SD & $46.0 \pm 15.9$ & $63.3 \pm 14.9$ & $0.067^{\mathrm{a}}$ \\
\hline Sex, male, $\mathrm{n}(\%)$ & $5(71.0)$ & $12(63.2)$ & $1.000^{\mathrm{b}}$ \\
\hline Smoking status, n (\%) & & & $0.805^{\mathrm{b}}$ \\
\hline Ex-smoker & $3(42.9)$ & $5 \quad(26.3)$ & \\
\hline Yes & $3(42.9)$ & $6 \quad(31.6)$ & \\
\hline No & $1(14.2)$ & $8(42.1)$ & \\
\hline Hypercholesterolemia, n (\%) & $0 \quad(0.0)$ & 13 (68.4) & $0.022^{\mathrm{b}}$ \\
\hline Hypertension, n (\%) & $5(71.4)$ & 14 (73.7) & $1.000^{\mathrm{b}}$ \\
\hline Diabetes, n (\%) & $2(28.6)$ & 4 (21.1) & $1.000^{\mathrm{b}}$ \\
\hline Renal failure, n (\%) & $0 \quad(0.0)$ & $1 \quad(5.3)$ & $1.000^{\mathrm{b}}$ \\
\hline $\mathrm{BCPO}, \mathrm{n}(\%)$ & $0 \quad(0.0)$ & $3(15.8)$ & $1.000^{\mathrm{b}}$ \\
\hline Coronary artery disease, $\mathrm{n}(\%)$ & $0 \quad(0.0)$ & $8(42.1)$ & $0.257^{\mathrm{b}}$ \\
\hline Aneurysm, n (\%) & & & $<0.001^{\mathrm{b}}$ \\
\hline Ascending aorta & $4(57.1)$ & $0 \quad(0.0)$ & \\
\hline Root & $0 \quad(0.0)$ & $19(100.0)$ & \\
\hline Valve dysfunction, n (\%) & $3(42.9)$ & $1 \quad(5.3)$ & $0.324^{\mathrm{b}}$ \\
\hline Drugs, n $(\%)$ & & & $0.563^{\mathrm{b}}$ \\
\hline ACE-inhibitors & $4(57.1)$ & 6 (31.6) & \\
\hline Beta-blockers & $2(28.6)$ & $10 \quad(52.6)$ & \\
\hline Beta-blockers/ACE inhibitors & $2(28.6)$ & 3 (15.8) & \\
\hline
\end{tabular}

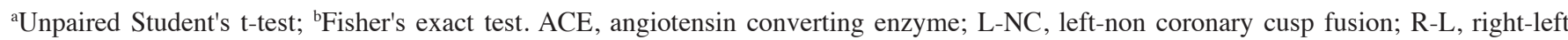
coronary cusp fusion; R-NC, right-non coronary cusp fusion; $\mathrm{BCPO}$, chronic obstructive pulmonary disease.

TUNEL assay. DNA fragmentation was examined using a TUNEL assay, which preferentially labels DNA strand breaks generated during apoptosis; specifically, the Fluorescein In situ Cell Death Detection kit (cat. no. 11684809910; Roche Applied Science) was used according to the manufacturer's protocol. The $5-\mu \mathrm{m}$ thick tissue sections of ascending aorta obtained from paraffin blocks, prepared as aforementioned, were dewaxed in xylene and rehydrated in decreasing alcohol steps (ethanol at $100,96,80,50 \%$ and distilled water). Then, the sections were incubated with proteinase $\mathrm{K}$ working solution at $37^{\circ} \mathrm{C}$ for $30 \mathrm{~min}$ for permeabilization and subsequently rinsed twice with PSB. Thereafter, the sections were treated with the TUNEL reaction mixture for $60 \mathrm{~min}$ at $37^{\circ} \mathrm{C}$ in the dark and rinsed three times with PBS. The nuclei were stained with Hoechst 33342 solution (1:1,000 in PBS; cat. no. 62249; Thermo Fisher Scientific, Inc.) for $15 \mathrm{~min}$ at room temperature. Finally, the coverslip was applied using PBS as the mounting medium and the stained sections were examined by a confocal microscope (Leica Confocal Microscope TCS SP8; Leica Microsystems, Inc.) and analyzed by Leica Application Suite advanced fluorescence software version 3.3.0. (Leica Microsystems, Inc.), and images of five random and non-overlapping fields were examined at an objective magnification of x200 for analysis.

Extraction of miRNA from aortic specimens and plasma. Ascending aortic wall biopsies were obtained during the surgical procedure and immediately stored at $-80^{\circ} \mathrm{C}$. Blood was withdrawn from patients before the surgical procedure and was processed within 90 min after collection. Plasma was obtained by centrifugation at $2,000 \mathrm{x}$ g for $15 \mathrm{~min}$ at $4^{\circ} \mathrm{C}$ and stored at $-80^{\circ} \mathrm{C}$ until needed. Total RNA including small RNA was isolated from aortic specimens using the RNeasy Mini Kit (cat. no. 74104; Qiagen $\mathrm{GmbH}$ ) and from plasma using the miRNeasy Serum/Plasma kit (cat. no. 217184; Qiagen GmbH) according to the manufacturer's instructions. The quantity and quality of total RNA were determined by a NanoDrop ND-1000 spectrophotometer (NanoDrop Technologies; Thermo Fisher Scientific, Inc.).

Reverse transcription-quantitative PCR (RT-qPCR). Reverse transcription was performed using the miScript II RT kit (cat. no. 218161; Qiagen $\mathrm{GmbH}$ ) according to the manufacturer's instructions. cDNA was pre-amplified using the miScript RT Kit (cat. no. 331451; Qiagen $\mathrm{GmbH}$ ), as previously described (17). qPCR analysis was performed using the miScript SYBR Green PCR Kit (Qiagen GmbH) at the following thermocycling conditions: $95^{\circ} \mathrm{C} 15 \mathrm{~min}$; and 40 cycles of $94^{\circ} \mathrm{C} 15 \mathrm{sec}, 55^{\circ} \mathrm{C} 30 \mathrm{sec}$ and $70^{\circ} \mathrm{C} 30 \mathrm{sec}$. The primers used are reported in Table II. miRNAs, including miR-718, miR-486, miR-130 and miR-122, were selected from the literature based on their previously reported association with aortopathies and vascular degeneration (18-20). miRNA expression levels were normalized to that of U6 snRNA and miR-16, and changes in the transcript level were calculated 
Table II. Primers used for reverse transcription-quantitative PCR.

Gene

$\begin{array}{ll}\text { Hs_miR-718_2 } & \text { MS00037856 } \\ \text { Hs_miR-486_1 } & \text { MS00004284 } \\ \text { Hs_miR-130a_1 } & \text { MS00003444 } \\ \text { Hs_miR-122a_1 } & \text { MS00003416 } \\ \text { Hs_RNU6-2_11 } & \text { MS00033740 } \\ \text { Hs_miR-16_2 } & \text { MS00031493 }\end{array}$

aPrimers were purchased from Qiagen, Inc. miR, microRNA; Hs, human.

using the $2^{-\triangle \Delta C q}$ method (21). qPCR was carried out using the Rotor-Gene $^{\mathrm{TM}} 6000$ Real-Time PCR Machine (Qiagen GmbH).

Statistical analyses. Unpaired Student's t-test and Fisher's test were conducted to compare, according to sex, all demographic and clinical features, comorbidity conditions and pharmacological treatments. The data obtained for MMP expression, TUNEL evaluation and miRNA expression were compared using one-way ANOVA followed by Bonferroni's post hoc test for multiple comparisons. The data are expressed as the mean \pm SD. The Kruskal-Wallis test and Dunn's post hoc test were used for comparisons of the distributions of non-normal variables in the three patient groups [control group $(\mathrm{CN})$, low-grade medial degeneration (LGMD) and high-grade medial degeneration (HGMD)] and for all multiple pairwise comparisons, respectively. A multivariate ordinal logit model (proportional odds model) was used to examine the predictors of disease. The ordinal logit model is a frequently-used method as it enables to ordinal variables to be modelled. In the ordinal logit model the cumulative probability of a level is connected to explanatory variables. In the present study, the response variable $\mathrm{Y}$ was classified into three response ordinal categories $\mathrm{CN}$, LGMD and $\mathrm{HGMD}$, with $\mathrm{CN}$ as the reference level. Indeed, in the proportional odds model $\mathrm{CN}$ was considered as reference category vs. cumulative remaining categories. The theory of logit model is reported on in previous studies (22-24). The explanatory variables that were considered in this model were: PL_miR-718, PL_miR-486, PL_miR-130, PL_miR122, TIS_miR-718, TIS_miR-486, TIS_miR-130 and TIS_miR122. Through the selection stepwise of LOGISTIC procedure of the Statistical Analysis Software (SAS) system the significant variables/predictors of model were identified. In stepwise selection, an attempt was made to remove any insignificant variables from the model before adding a significant variable to the model: Significance level of 0.05 was required to allow a variable into the model and a significance level of 0.05 was required for a variable to stay in the model (the score chi-square was used to determine entry; the Wald chi-square was used to determine removal). Results are presented as the adjusted odds ratios (ORs) with $95 \%$ confidence interval only for variables/predictors that were significant in stepwise selection of LOGISTIC procedure. Statistical analysis was performed using the SAS 9.4 programme (SAS Institute, Inc.). $\alpha<0.05$ or $\mathrm{P}<0.05$ were considered to indicate a statistically significant difference.

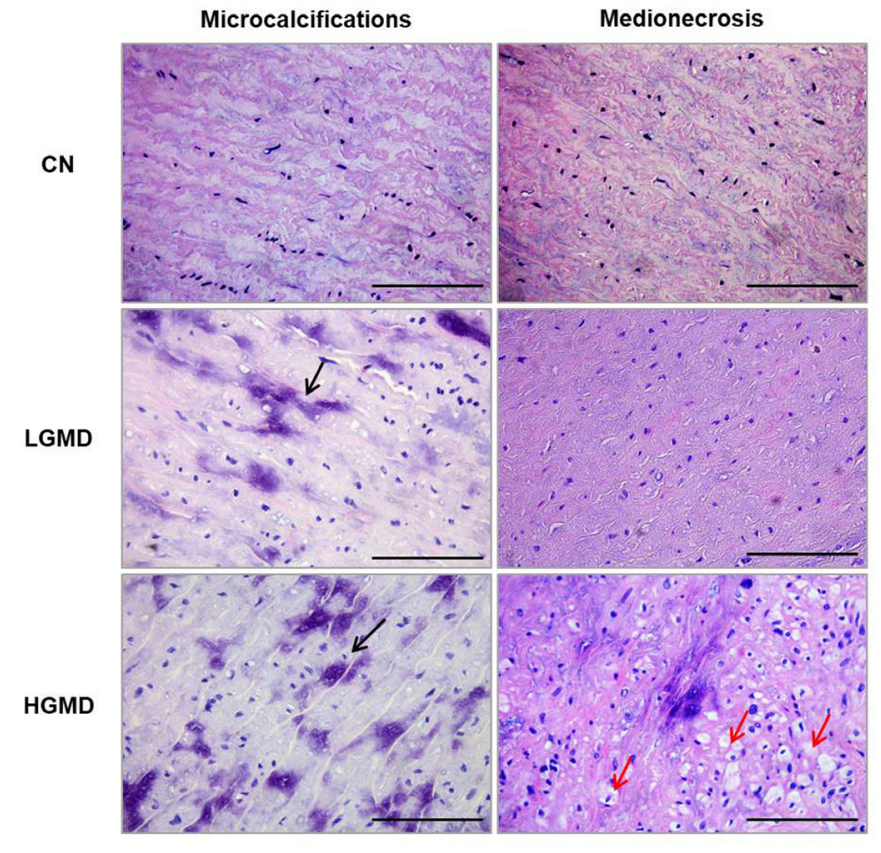

Figure 1. H\&E staining of the ascending aortic wall. Histological evaluation of the ascending aortic walls demonstrating focal to diffuse microcalcifications (black arrows) of the medial tunica, as well as absent to multifocal areas of smooth muscle destruction (medionecrosis, red arrows) in all three groups, which indicated tissue damage. Magnification, $\mathrm{x} 400$; scale bar, $100 \mu \mathrm{m}$. CN, control; HGMD, high-grade medial degeneration; LGMD, low-grade medial degeneration.

\section{Results}

Clinical data and histological evaluation. The histological evaluation of the ascending aortic wall showed focal to diffuse microcalcifications of the medial tunica, absent to multifocal areas of the destruction of the smooth muscle, such as medionecrosis (Fig. 1), focal to multicentric elastic fragmentation (Fig. 2A), low levels to large increase of collagen content (Fig. 2B) and sporadic to consistent accumulation of PAS-positive material (Fig. 2C). Using the criteria adapted from Schlatmann and Becker (13) and de Sa et al (14), an ascending aortic wall score was determined and according to this score two groups of patients with BAV were identified: i) LGMD (mean aortic wall score, 5.75 \pm 0.96 ), with focal or absent medionecrosis, foci of elastic fragmentation, faint and sporadic accumulation of mucoid material, and faint or focal increase of interstitial collagen in some areas of the media; and ii) HGMD (mean aortic wall score, 9.25 \pm 1.5 ), with severe medionecrosis, a number of foci of elastic fragmentation, consistent accumulation of mucoid material and accumulation of collagen in more than a third of the media. Both groups consisted of 13 patients, the LGD group consisted of 9 R-L, 3 R-NC and 1 L-NC BAV phenotypes, whereas the HGD group consisted of $10 \mathrm{R}-\mathrm{L}$, 2 R-NC and 1 L-NC BAV phenotypes. The morphological analyses indicated that the grade of medial degeneration was independent from the BAV phenotype. In the samples of the $\mathrm{CN}$ group, no morphological alterations were observed in the media of the ascending aortic wall (Figs. 1 and 2; Table III).

Ascending aorta from the HGD group showed increased expression of MMP-9 and MMP-2. The percentage of 
CN
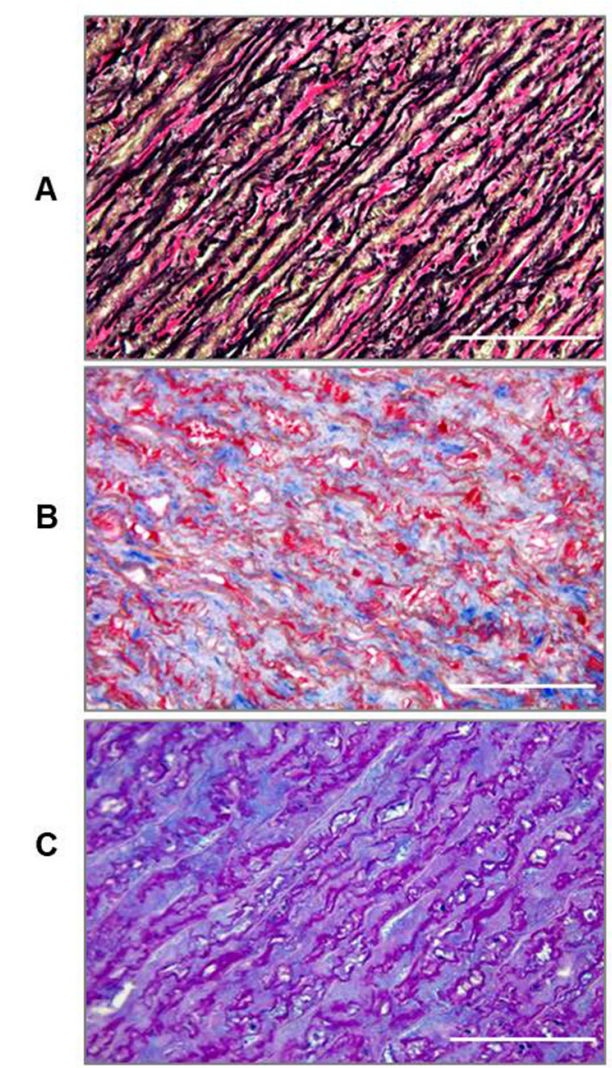

LGMD
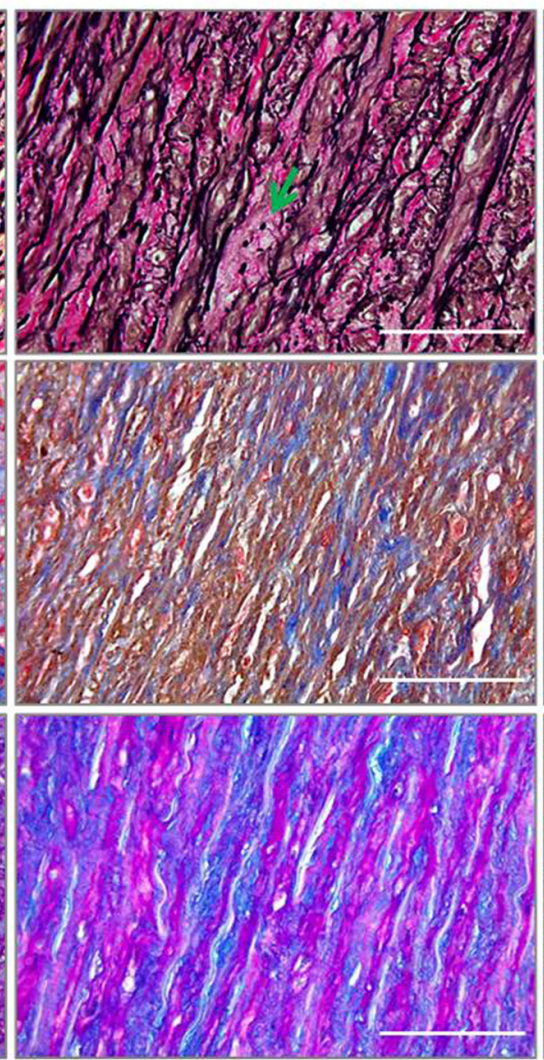

HGMD
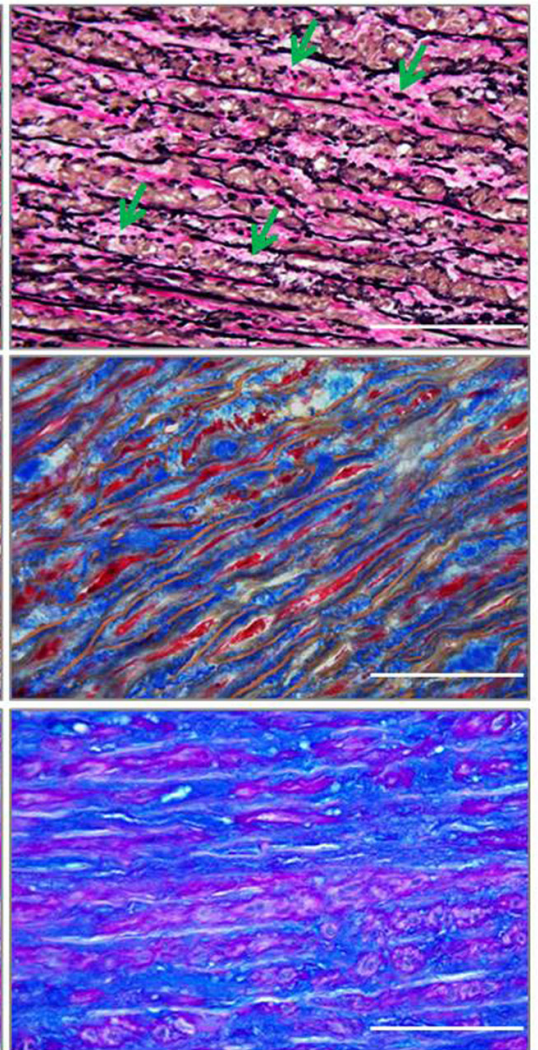

Figure 2. Weigert-van Gieson, Masson's Trichrome and Alcian PAS staining of the ascending aortic wall. (A) Representative images of elastic Weigert-van Gieson staining of the ascending aortic wall. The specimens showed focal elastic fragmentation in the LGD group (green arrow), and multicentric areas of elastic fragmentation in the HGD group (green arrows), thus indicating elastic degeneration of the medial tunica. (B) Representative images of Masson's Trichrome staining of the ascending aortic wall that show the collagen content (blue staining) in the medial tunica. In particular, there was a large increase in the collagen content observed in the HGD group, which suggested the connective tissue remodeling of the aortic wall. (C) Representative images of Alcian PAS staining of the ascending aortic wall that shows the accumulation of mucoid material (blue staining). The LGD group presented with the sporadic accumulation of mucoid material, whereas the HGD group showed a consistent accumulation of mucoid material. Magnification, $\mathrm{x} 400$; scale bar, $100 \mu \mathrm{m}$. CN, control; HGMD, high-grade medial degeneration; LGMD, low-grade medial degeneration; PAS, periodic acid-Schiff.

MMP2- and MMP9-stained cells was calculated following immunohistochemistry. The levels of MMP2 and MMP9 immunoreactivity were both significantly increased in the HGD group compared with the LGMD and CN groups (both $\mathrm{P}<0.001$; Fig. 3A and B).

Ascending aorta from HGD group have apoptotic cells in the medial tunica. TUNEL assay results showed an increase of the number of apoptotic cells in the HGD group and focal apoptotic cells were observed in the LGD group compared with the control. The apoptotic cells were observed in the subintimal region of the media, which confirmed the severity of damage of the ascending aortic wall. Apoptosis in the HGD group was significantly increased compared with the $\mathrm{CN}$ group $(\mathrm{P}<0.001$; Fig. 4A and B).

Significance of tissue and plasma miR-718, miR-486, miR-130 and miR-122 expression levels in relation to the ascending aortic wall score. miRNA expression analysis of the ascending aortic wall showed a significant downregulation of the tissue expression levels of miR-718 and miR-122 in the LGMD and HGD groups compared with the $\mathrm{CN}$ group $(\mathrm{P}<0.01$ and $\mathrm{P}<0.05$, respectively; Fig. 5A). Notably, the HGD group exhibited a significant increase of the tissue expression levels of miR-486 compared with those of the LGMD and $\mathrm{CN}$ groups $(\mathrm{P}<0.05$; Fig. 5A). No significant difference was identified for the tissue expression levels of miR-130 between the three groups (Fig. 5A).

Significant differences among the LGMD, HGMD and CN groups for miR-718, miR-486, miR-130 and miR-122 in both tissue and plasma were analyzed by Kruskal-Wallis test (Table IV). To improve the understanding of the significance of these markers, Dunn's post hoc test and multivariate (multivariate analysis adjusted OR, 95\% CI) analyses were also performed. The comparison of the tissue expression levels of miR-718, miR-486, miR-130 and miR-122 between CN, LGMD and HGD groups showed significant differences (Table IV). In particular the Dunn's post hoc test showed a significant decrease of miR-718 tissue expression levels in the LGMD and HGD groups compared with the $\mathrm{CN}$ group $(\mathrm{P}<0.001$ and $\mathrm{P}<0.05$, respectively; Table IV). In addition, the analysis confirmed the data regarding the upregulation of the tissue expression levels of miR-486 in the HGD group compared with the LGD group $(\mathrm{P}<0.001$; Table IV). The Dunn's post hoc test showed the decrease of miR-486 tissue expression levels in the LGD group compared with the 
Table III. Histopathological features of the ascending aortic wall.

\begin{tabular}{|c|c|c|c|c|}
\hline \multirow[b]{2}{*}{ Histopathological features } & \multicolumn{2}{|c|}{ Control group (n=12) } & \multicolumn{2}{|c|}{$\begin{array}{c}\text { Bicuspid aortic } \\
\text { valve group }(n=26)\end{array}$} \\
\hline & $\mathrm{n}$ & $\%$ & $\mathrm{n}$ & $\%$ \\
\hline \multicolumn{5}{|l|}{ Microcalcifications } \\
\hline 0 & 8 & 67 & 0 & 0 \\
\hline I & 4 & 33 & 6 & 23 \\
\hline II & 0 & 0 & 12 & 46 \\
\hline III & 0 & 0 & 8 & 31 \\
\hline \multicolumn{5}{|l|}{ Medionecrosis } \\
\hline 0 & 12 & 100 & 7 & 27 \\
\hline I & 0 & 0 & 5 & 19 \\
\hline II & 0 & 0 & 6 & 23 \\
\hline III & 0 & 0 & 8 & 31 \\
\hline \multicolumn{5}{|l|}{ Elastic fiber fragmentation } \\
\hline 0 & 11 & 92 & 0 & 0 \\
\hline I & 1 & 8 & 8 & 31 \\
\hline II & 0 & 0 & 11 & 42 \\
\hline III & 0 & 0 & 7 & 27 \\
\hline \multicolumn{5}{|l|}{ Collagen accumulation } \\
\hline 0 & 10 & 83 & 3 & 11 \\
\hline I & 2 & 17 & 10 & 39 \\
\hline II & 0 & 0 & 8 & 31 \\
\hline III & 0 & 0 & 5 & 19 \\
\hline \multicolumn{5}{|c|}{ PAS-positive material accumulation } \\
\hline 0 & 12 & 100 & 0 & 0 \\
\hline I & 0 & 0 & 12 & 46 \\
\hline II & 0 & 0 & 4 & 15 \\
\hline III & 0 & 0 & 10 & 39 \\
\hline
\end{tabular}

PAS, periodic acid-Schiff.

$\mathrm{CN}$ group $(\mathrm{P}<0.05)$. Moreover, miR-130 tissue expression levels were decreased in the LGD group compared with the $\mathrm{CN}$ and HGD groups $(\mathrm{P}<0.001$ and $\mathrm{P}<0.05$, respectively). Finally, miR-122 tissue expression levels were decreased in the LGMD and HGD groups compared with the $\mathrm{CN}$ group $(\mathrm{P}<0.01$ and $\mathrm{P}<0.05$, respectively).

Plasma circulating levels of miR-718 were significantly decreased in the HGD group compared with the $\mathrm{CN}$ and LGD groups $(\mathrm{P}<0.01$; Fig. 5B), whereas miR-122 levels were significantly decreased in the LGMD and HGD groups compared with the $\mathrm{CN}$ group $(\mathrm{P}<0.001$; Fig. 5B). Notably, plasma expression levels of miR-486 were significantly increased in the LGMD and HGD groups compared with the $\mathrm{CN}$ group $(\mathrm{P}<0.01)$. No significant differences were identified for miR-130 plasma expression levels between the three groups.

Kruskal-Wallis and Dunn's post hoc test (Table IV) showed that miR-718 plasma expression levels were significantly decreased in the LGD group compared with the CN group $(\mathrm{P}<0.001)$, whereas miR-486 plasma expression levels were increased in the LGMD and HGD groups compared with the
$\mathrm{CN}$ group $(\mathrm{P}<0.01$ and $\mathrm{P}<0.001$, respectively). miR-130 plasma expression levels were increased only in the LGD group compared with the $\mathrm{CN}$ group $(\mathrm{P}<0.001)$ and miR-122 expression levels were decreased in both the LGMD and HGD groups compared with the $\mathrm{CN}$ group $(\mathrm{P}<0.01)$.

In addition, it was observed that in the multivariate analysis, although plasma and tissue expression levels of miR-718, miR-486, miR-130 and miR-122 were included in the model, only the plasmid levels of miR-486 showed a significant change [odds ratio (OR) 2.467; 95\% CI, 1.407-4.327; Table IV]. The OR analysis obtained with the logit model, suggested that statistically the increase of miR-486 increased the risk of damage in the ascending aortic wall (increase of a point of plasma miR-486 produced an increase equal to 2.467 of the risk of being LGMD or HGMD compared with the $\mathrm{CN}$ group).

\section{Discussion}

Current guidelines on the treatment of ascending aortic aneurysm associated with non-BAV disease suggest surgical repair at aortic diameter $\geq 55$ or $\geq 50 \mathrm{~mm}$ when additional 


\section{A}

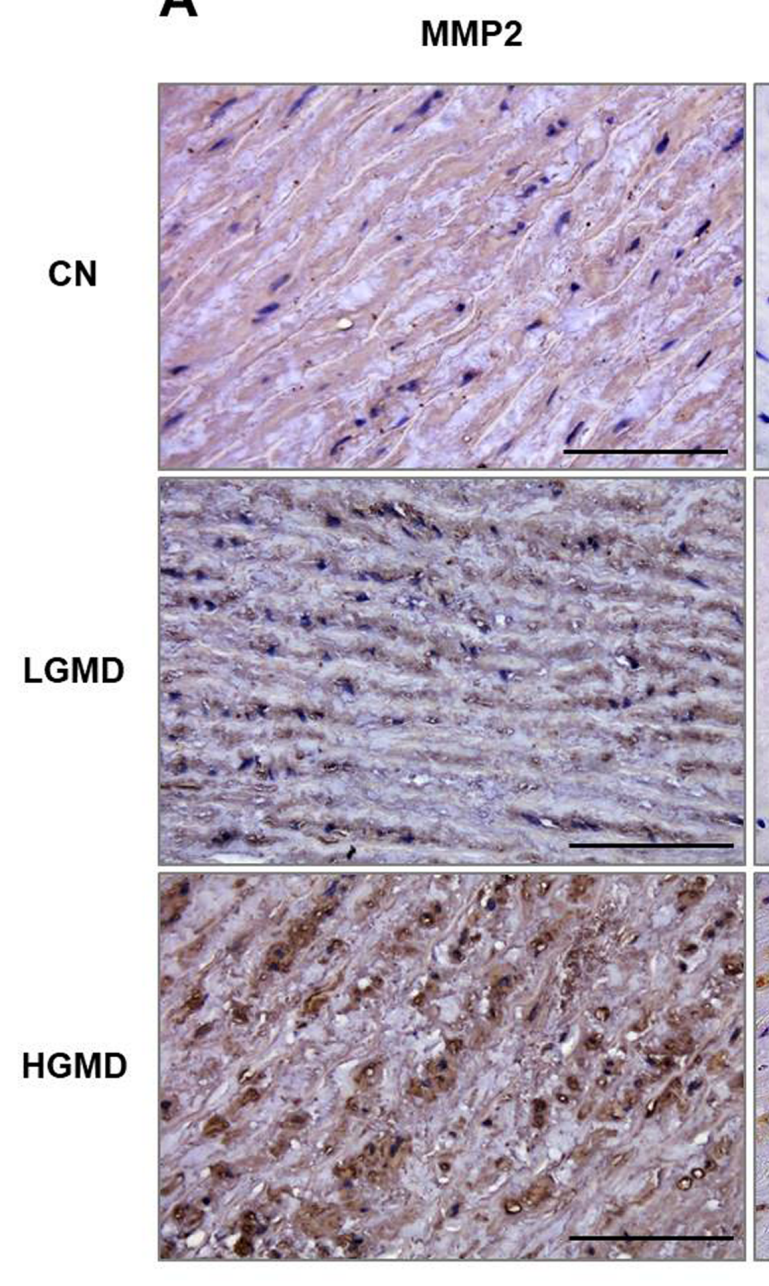

B

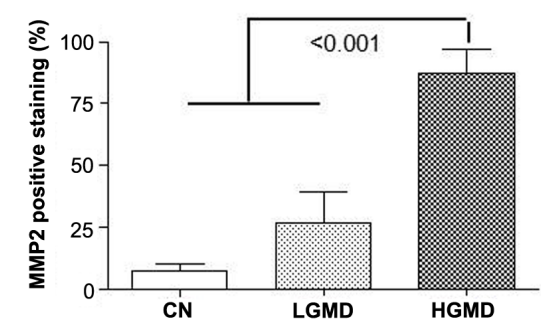

MMP9
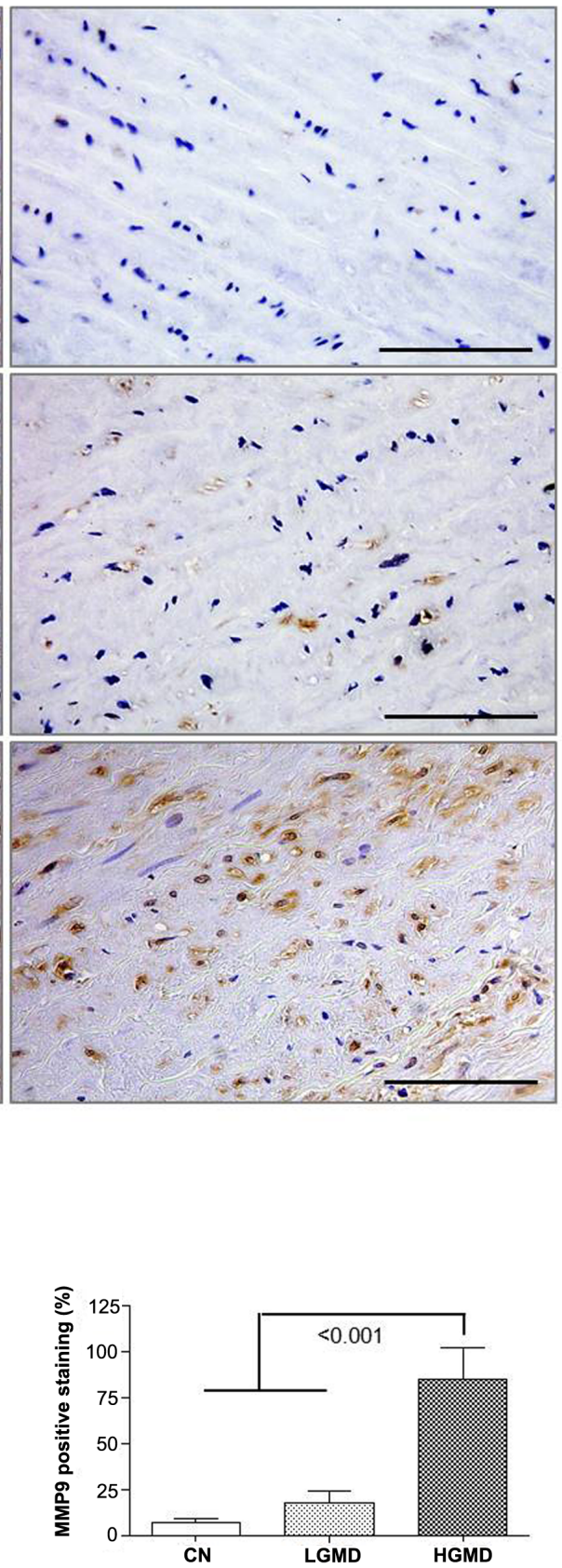

Figure 3. MMP2 and MMP9 expression in the ascending aortic wall determined by immunohistochemistry. (A) Representative images of MMP2-positive (left) and MMP9-positive (right) stained cells in ascending aortic wall samples. Magnification, x400; scale bar, $100 \mu \mathrm{m}$. (B) Quantitative analysis demonstrating that the tissue expression levels of MMP2 and MMP9 were both significantly increased in the HGD group compared with the LGMD and CN groups (P<0.001). Data are presented as the mean \pm SD. CN, control; HGMD, high-grade medial degeneration; LGMD, low-grade medial degeneration.

risk factors or coarctation are present; when surgery is primarily indicated for BAV, replacement of aortic root or tubular ascending aorta should be considered at $\geq 45 \mathrm{~mm}$ maximum diameter (25). The risk of rupture and acute dissection increases significantly once a diameter of $50 \mathrm{~mm}$ is reached (26), nevertheless, acute aortic dissection in patients with BAV can occur at smaller sizes than generally perceived. Svensson and Khitin (27) assessed that in patients with BAV dissected at a maximum diameter of $<50 \mathrm{~mm}$ (18). In addition, the risk of dissection in BAV appears to be comparable to patients with Marfan syndrome, but it can occur more frequently as BAV can present in $1-2 \%$ of the population (28). Acute aortic dissection may occur at a younger age in patients with BAV; data from The International Register for Acute Aortic Dissection suggested that patients under the age of 40 who suffered type A aortic dissection more often had BAV compared with those dissecting over the age of 40 (9 vs. 1\%; $\mathrm{P}<0.01)$ and these patients dissected at ascending aortic diameter $<50 \mathrm{~mm}$ (29). There is, in our opinion, a discrepancy between current guidelines, and increasing data from 
A

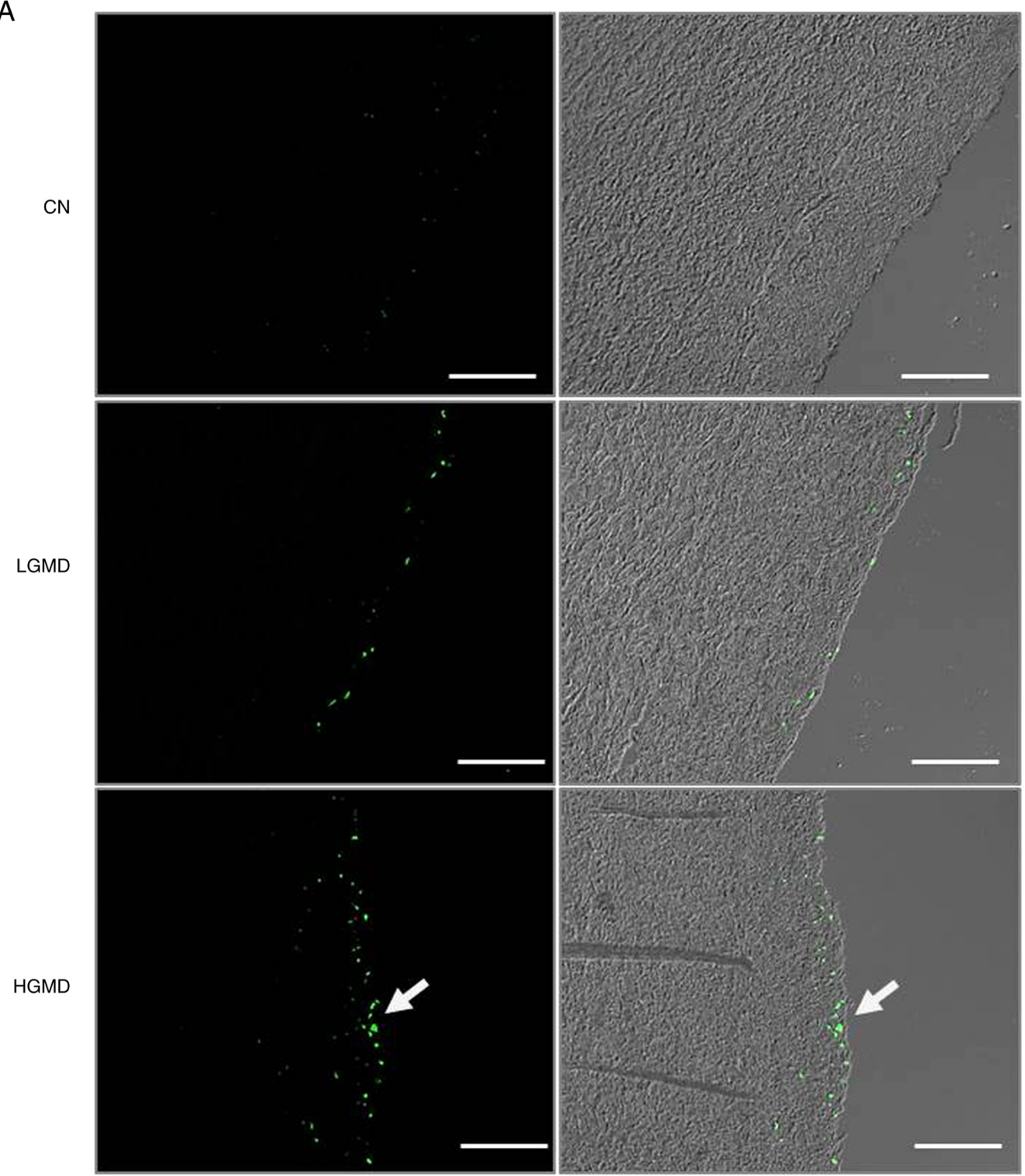

B

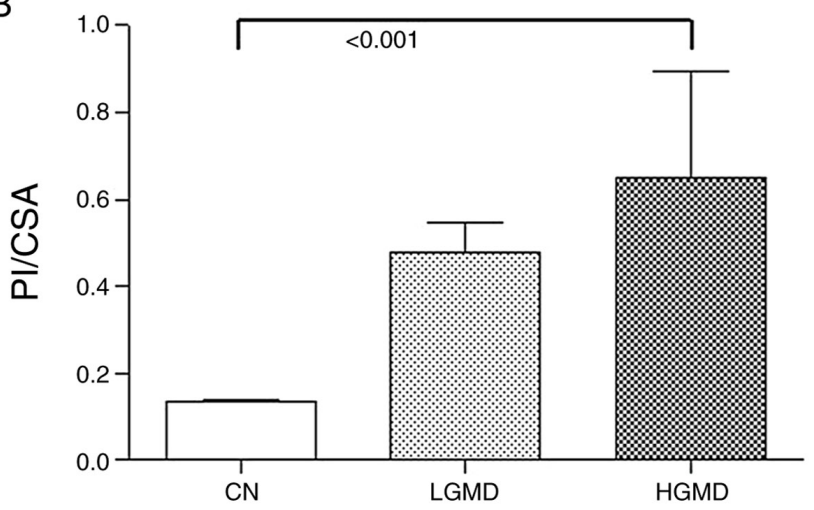

Figure 4. Confocal microscopy analysis of apoptosis in the aortic wall by TUNEL. (A) Representative fluorescence images showing apoptotic cells in the medial tunica (green, left); merged phase contrast images (right). Magnification, x200; scale bar, $100 \mu \mathrm{m}$. (B) Quantification of the TUNEL results from part (A). The data are expressed as the mean PI normalized to the CSA using the Leica Application Suite advanced fluorescence software. Data are presented as the mean \pm SD. The TUNEL assay revealed an increase in the number of apoptotic cells in the subintimal region (white arrows) in the HGD group and focal apoptotic cells in the LGD group. CN, control; CSA, cross-sectional area; HGMD, high-grade medial degeneration; LGMD, low-grade medial degeneration; PI, pixel intensity.

international literature (30) has suggested that surgical repair of ascending aortic aneurysm in patients with BAV should be performed at a smaller diameter than the ones suggested ( $\geq 55$ or $\geq 50 \mathrm{~mm}$ ). Aortic dissection and rupture is 'often' 
A
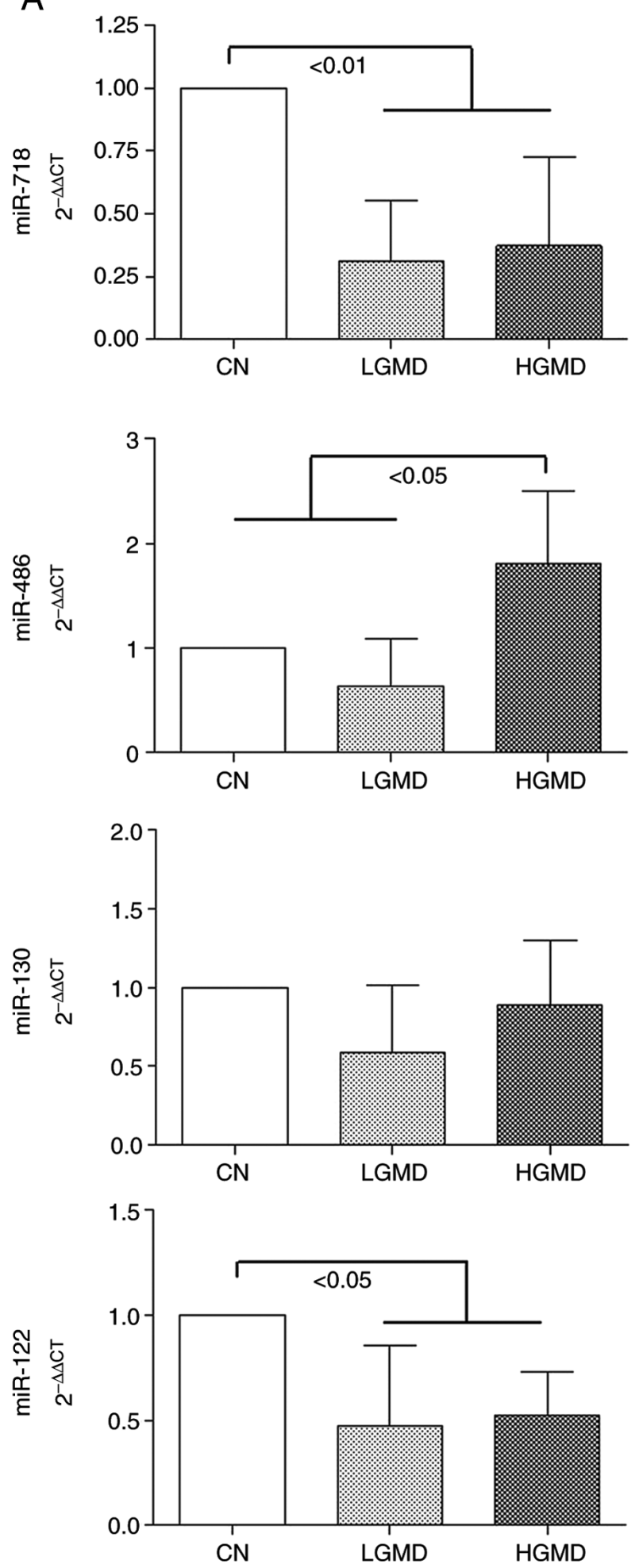

B
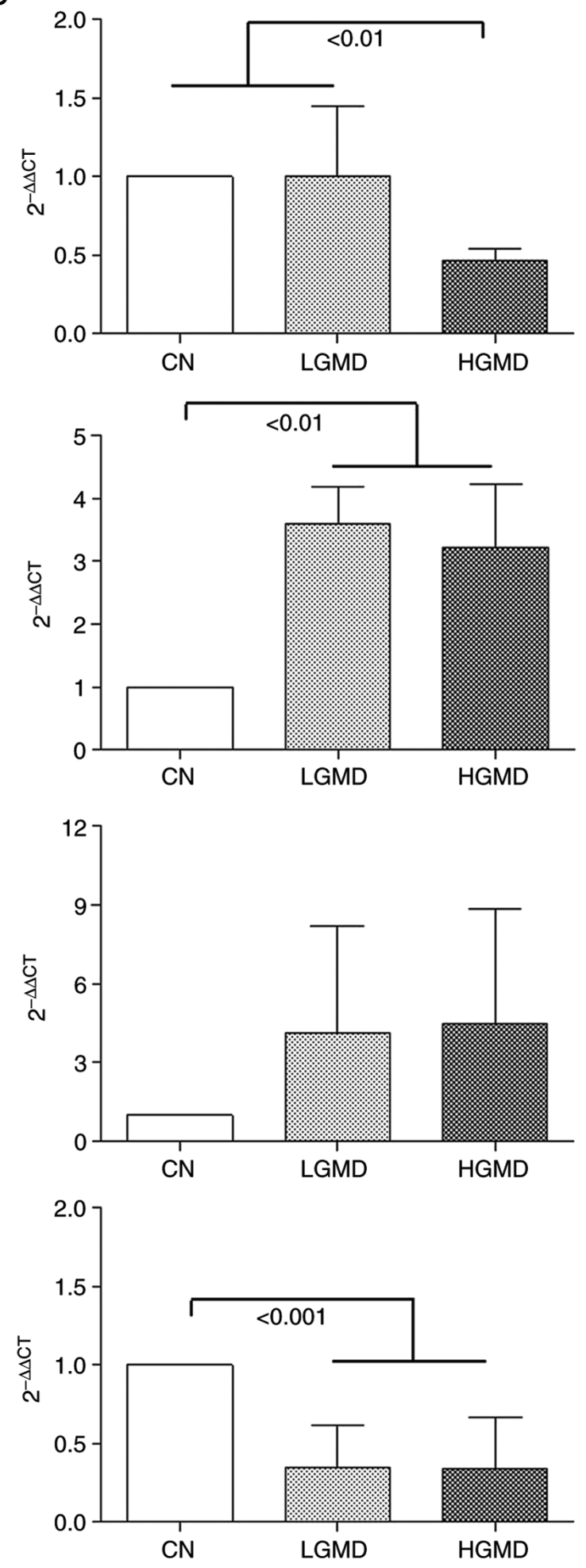

Figure 5. Reverse transcription-quantitative PCR evaluation of the expression levels of miR-718, miR-486, miR-130 and miR-122. (A) miRNA expression levels in the ascending aortic wall tissue. The results demonstrate that there were significant decreases in the tissue expression levels of miR-718 and miR-122 in the LGMD and HGD groups compared with the CN group, and a significant increase in the miR-486 expression level in the HGD group compared with the CN and LGD groups. (B) miRNA expression levels in the plasma. The results demonstrate a significant decrease of miR-718 in the HGD group compared with the CN and LGD groups, and a significant decrease of miR-122 in the HGMD and LGD groups compared with the CN group. miR-486 was significantly increased in the LGMD and HGD groups compared with the CN group. Data are presented as the mean $\pm \mathrm{SD}$. CN, control; HGMD, high-grade medial degeneration; LGMD, low-grade medial degeneration; miR/miRNA, microRNA.

associated with severe aortic wall degeneration and, to be able to link the grade of medial tunica degeneration to specific plasma biomarkers, might be of help in preventing deadly complications, such as dissection and rupture. The present 
Table IV. Comparison of miRNA expression levels in the patient groups.

\begin{tabular}{|c|c|c|c|c|c|c|}
\hline \multirow[b]{2}{*}{ Predictor } & \multirow{2}{*}{$\begin{array}{l}\text { Patient } \\
\text { group }\end{array}$} & \multirow[b]{2}{*}{ Median (range) } & \multicolumn{3}{|c|}{ Univariate analysis } & \multirow{2}{*}{$\begin{array}{l}\text { Multivariate analysis, } \\
\text { adjusted } \mathrm{OR}^{\mathrm{c}}(95 \% \mathrm{CI})\end{array}$} \\
\hline & & & P-value ${ }^{a}$ & Comparison & P-value ${ }^{b}$ & \\
\hline \multirow[t]{3}{*}{ PL_miR-718 } & $\mathrm{CN}$ & $1.000(1.000-1.000)$ & $<0.001$ & CN vs. LGMD & $<0.001$ & NS \\
\hline & LGMD & $0.393(0.259-0.591)$ & & CN vs. HGMD & NS & \\
\hline & HGMD & $0.686(0.384-1.084)$ & & LGMD vs. HGMD & NS & \\
\hline \multirow[t]{3}{*}{ PL_miR-486 } & $\mathrm{CN}$ & $1.000(1.000-1.000)$ & $<0.001$ & CN vs. LGMD & $<0.010$ & $2.467(1.407-4.327)$ \\
\hline & LGMD & 4.714 (2.027-9.459) & & CN vs. HGMD & $<0.001$ & \\
\hline & HGMD & $9.541(4.869-14.075)$ & & LGMD vs. HGMD & NS & \\
\hline \multirow[t]{3}{*}{ PL_miR-130 } & $\mathrm{CN}$ & $1.000(1.000-1.000)$ & $<0.001$ & CN vs. LGMD & $<0.001$ & NS \\
\hline & LGMD & $3.441(1.913-10.193)$ & & CN vs. HGMD & NS & \\
\hline & HGMD & $1.260(0.350-12.010)$ & & LGMD vs. HGMD & NS & \\
\hline \multirow[t]{3}{*}{ PL_miR122 } & $\mathrm{CN}$ & $1.000(1.000-1.000)$ & $<0.002$ & CN vs. LGMD & $<0.010$ & NS \\
\hline & LGMD & $0.124(0.012-1.491)$ & & CN vs. HGMD & $<0.010$ & \\
\hline & HGMD & $0.185(0.042-1.295)$ & & LGMD vs. HGMD & NS & \\
\hline \multirow[t]{3}{*}{ TIS_miR-718 } & $\mathrm{CN}$ & $1.000(1.000-1.000)$ & $<0.001$ & CN vs. LGMD & $<0.001$ & NS \\
\hline & LGMD & $0.362(0.271-0.428)$ & & CN vs. HGMD & $<0.050$ & \\
\hline & HGMD & $0.575(0.294-1.070)$ & & LGMD vs. HGMD & NS & \\
\hline \multirow[t]{3}{*}{ TIS_miR-486 } & $\mathrm{CN}$ & $1.000(1.000-1.000)$ & $<0.001$ & $\mathrm{CN}$ vs. LGMD & $<0.050$ & NS \\
\hline & LGMD & $0.590(0.398-1.179)$ & & CN vs. HGMD & NS & \\
\hline & HGMD & $2.229(0.796-3.266)$ & & LGMD vs. HGMD & $<0.001$ & \\
\hline \multirow[t]{3}{*}{ TIS_miR-130 } & $\mathrm{CN}$ & $1.000(1.000-1.000)$ & $<0.001$ & CN vs. LGMD & $<0.001$ & NS \\
\hline & LGMD & $0.544(0.187-0.877)$ & & CN vs. HGMD & NS & \\
\hline & HGMD & $0.821(0.523-1.380)$ & & LGMD vs. HGMD & $<0.050$ & \\
\hline \multirow[t]{3}{*}{ TIS_miR122 } & $\mathrm{CN}$ & $1.000(1.000-1.000)$ & $<0.007$ & $\mathrm{CN}$ vs. LGMD & $<0.010$ & NS \\
\hline & LGMD & $0.513(0.145-1.235)$ & & CN vs. HGMD & $<0.050$ & \\
\hline & HGMD & $0.693(0.356-1.216)$ & & LGMD vs. HGMD & NS & \\
\hline
\end{tabular}

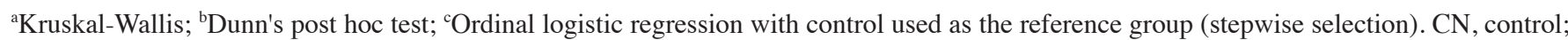
NS, not significant; HGMD, high-grade medial degeneration; LGMD, low-grade medial degeneration; miR/miRNA, microRNA; OR, odds ratio; PL, plasma levels; TIS, tissue.

study investigated the involvement of miR-718, miR-486, miR-130 and miR-122 in patients with BAV with regard to aortic wall degeneration. This research started from the assumption that, in patients with BAV with ascending aortic aneurysm or dissection, the pathological changes may involve the ascending aortic portion, as well as the non-dilated aortic root (31). The presence of BAV may lead to abnormal blood flow and shear stress at the ascending aorta, thus causing apoptosis of the endothelial cells, inflammation, oxidative stress and extracellular matrix (ECM) remodeling (32). Moreover, in our hypothesis, circulating miRNAs may be involved in the paracrine communication between cells contributing to the regulation of the disease progression. The determination of circulating biomarkers of aortic histological abnormalities may be useful for the identification of novel biomarkers that could significantly improve the diagnosis, prognosis and treatment of BAV.

Previously, different types of aneurysm related to BAV morphology have been described $(33,34)$. In particular, it seems that a specific aneurysm characterized by root enlargement is frequently associated with the R-L BAV phenotype. This form of aneurysm involves the young BAV population, and being male increases the risk of developing this condition. A previous study supported the predominant genetic origin of BAV root aneurysm type, reporting a TGF- $\beta$ receptor type- 2 gene mutation (35). The histological analysis conducted in the present study showed that the severity of medial degeneration of the ascending aortic wall was not associated with a specific BAV phenotype; thus, after morphological evaluation, patients were divided into two groups according to the grade of their medial degeneration score. The two groups were composed of patients with different types of BAV phenotypes. However, the prevailing phenotype of BAV was the R-L phenotype. The HGD group showed increased immunoreactivity for MMP2 and MMP9, which is in accordance with other studies that have reported an association between the overexpression of MMPs in medial and aortic aneurysm (36-38). The risk of aortic dissection could be enforced by the presence of multicentric areas of elastic fragmentation, massive increases of collagen content and apoptotic cells in the media, as demonstrated by the results of the present study. Furthermore, the identification of easily detectable biomarkers of the grade of ascending aortic wall degeneration could reduce mortality related to aortic complications. 
The miRNAs examined in the current study were chosen based on their previously reported association with aortopathies (18-20). The expression levels of miR-718, miR-486, miR-130 and miR-122 were first investigated in the tissue specimens of the ascending aortic wall, followed by detection in circulation (plasma) to determine whether there was an association between aortic damage and variation in the expression levels of miRNAs. The data obtained showed an association between tissue and circulating levels of these miRNAs. In multivariate analysis, the estimate of odds ratio for miR-486 indicated that high levels of miR-486 might be associated with a high risk of having high scores of damage in the ascending aortic wall. It has been demonstrated that miR-122, miR-130a and miR-486 regulation is dependent on the tricuspid or bicuspid morphology of the aortic valve, and miR-718 may be considered as a biomarker of aortic dilatation (20). Moreover, miR-122 and miR-130a are molecular effectors in the BAV-associated dysregulation of TGF- $\beta 1$ receptor. TGF- $\beta 1$ mediates tissue fibrosis and ECM remodeling in ascending aorta (20). The present study results support the idea that the regulation of these miRNAs may be associated with ascending aortic wall damage.

miRNAs are known to be versatile master regulators of signaling pathways owing to their capacity to modulate the expression of crucial components of signal transduction at multiple levels. Thus, these candidate miRNAs, and in particular miR-486 and miR-122, may be potential biomarkers of the risk of rupture and dissections in patients with BAV. Moreover, the evaluation of miRNA levels in plasma is reproducible and consistent among individuals, being protected from endogenous ribonuclease-induced degradation $(39,40)$. As an added value, plasma is a biological specimen more easily accessible by non-invasive means compared to other tissues, which might improve the feasibility of these molecules as useful biomarkers in routine clinical practice.

In conclusion, we proposed that miR-122, miR-130, miR-718 and miR-486 are novel molecular features associated with severe medial degeneration in patients with BAV with aortic dilatation. In particular, as aforementioned, miR-486 could be considered as a new non-invasive biomarker of aortic wall degeneration in BAV owing to its association with the morphological features of the vessel. A significant dysregulation of this biomarkers might be associated with high risk of dissection and rupture of the ascending aortic diameter.

\section{Acknowledgements}

Not applicable.

\section{Funding}

The present work was supported by CARDIOSERVICE SAS.

\section{Availability of data and materials}

The datasets used and/or analyzed during the current study are available from the corresponding author on reasonable request.

\section{Authors' contributions}

CP, AMG, FR, VAg and FC were responsible for the conception of the present study. CP, AT, VAg, GR and VAr acquired the clinical and surgical data. AMG, FR, RB, AP and FC acquired the histological, immunohistochemical and mRNA data. CP, AMG, FR, FC, GR and VAr analyzed and interpreted the data. RA was responsible for statistical analysis. All authors drafted the work and revised it critically for important intellectual content. All authors have read and approved the final manuscript. CP, AMG, FR, FC and VAr confirm the authenticity of all the raw data.

\section{Ethics approval and consent to participate}

This study was approved by the Institutional Review Board of University of Palermo (approval no. CE 2A17-000-527-28; Palermo, Italy). Written informed consent was obtained from all participants

\section{Patient consent for publication}

Not applicable.

\section{Competing interests}

The authors declare that they have no competing interests.

\section{References}

1. Masri A, Svensson LG, Griffin BP and Desay MY: Contemporary natural history of bicuspid aortic valve disease: A systematic review. Heart 103: 1323-1330, 2017.

2. Michelena HI, Desjardins VA, Avierinos JF, Russo A, Nkomo VT, Sundt TM, Pellikka PA, Tajik AJ and Enriquez-Sarano M: Natural history of asymptomatic patients with normally functioning or minimally dysfunctional bicuspid aortic valve in the community. Circulation 117: 2776-2784, 2008.

3. Abdulkareem N, Smelt J and Jahangiri M: Bicuspid aortic valve aortopathy: Genetics, pathophysiology and medical therapy. Interact Cardiovase Thorac Surg 7: 554-559, 2013.

4. Liu T, Xie M, Lv Q, Li Y, Fang L, Zhang L, Deng W and Wang J: Bicuspid aortic valve: An update in morphology, genetics, biomarker, complications, imaging diagnosis and treatment. Front Physiol 9: 1921, 2018.

5. Niaz $\mathrm{T}$ and Hagler DJ: Is there a genetic basis to the different morphological subtypes of bicuspid aortic valve? Ann Transl Med 6 (Suppl 2): S117, 2018.

6. Harrison OJ, Visan AC, Moorjani N, Modi A, Salhiyyah K, Torrens C, Ohri S and Cagampang FR: Defective NOTCH signaling drives increased vascular smooth muscle cell apoptosis and contractile differentiation in bicuspid aortic valve aortopathy: A review of the evidence and future directions. Trends Cardiovasc Med 29: 61-68, 2019.

7. Miller RL, Diamonstein CJ and Benheim A: The importance of genetics and genetic counselors in the evaluation of patients with bicuspid aortic valve and aortopathy. Curr Opin Cardiol 34: 73-78, 2019.

8. Balistreri CR, Crapanzano F, Schirone L, Allegra A, Pisano C, Ruvolo G, Forte M, Greco E, Cavarretta E, Marullo AG, et al: Deregulation of notch1 pathway and circulating endothelial progenitor cell (EPC) number in patients with bicuspid aortic valve with and without ascending aorta aneurysm. Sci Rep 8: 13834, 2018.

9. Sievers HH, Stierle U, Hachmann RMS and Charitos El: New insights in the association between bicuspid aortic valve phenotype, aortic configuration and valve haemodynamics. Eur J Cardiothorac Surg 49: 439-446, 2016.

10. McKusick VA: Association of congenital bicuspid aortic valve and Erdheim's cystic medial necrosis. Lancet 1: 1026-1027, 1972. 
11. Kouchoukos NT, Wareing TH, Murphy SF and Perrillo JB: Sixteen-year experience with aortic root replacement. Results of 172 operations. Ann Surg 214: 308-318, 1991.

12. Bellavia M, Rappa F, Lo Bello M, Brecchia G, Tomasello G, Leone A, Spatola G, Uzzo ML, Bonaventura G, Davis S, et al Lactobacillus casei and Bifidobacterium lactis supplementation reduces tissue damage of intestinal mucosa and liver after 2,4,6-trinitrobenzenesulfonic acid treatment in mice. J Biol Regul Homeost Agents 28: 251-261, 2014

13. Schlatmann TJ and Becker AE: Histologic changes in the normal aging aorta: Implications for dissecting aortic aneurysm. Am J Cardiol 39: 13-20, 1977.

14. de Sa M, Moshkovitz Y, Butany J and David TE: Histologic abnormalities of the ascending aorta and pulmonary trunk in patients with bicuspid aortic valve disease: Clinical relevance to the ross procedure. J Thorac Cardiovasc Surg 118: 588-594, 1999.

15. Barone R, Rappa F, Macaluso F, Bavisotto CC, Sangiorgi C Di Paola G, Tomasello G, Di Felice V, Marcianò V, Farina F, et al: Alcoholic liver disease: A mouse model reveals protection by lactobacillus fermentum. Clin Transl Gastroenterol 7: e138, 2016

16. Rappa F, Sciume C, Lo Bello M, Bavisotto CC, Gammazza AM, Barone R, Campanella C, Davis S, Carini F, Zarcone F, et al: Comparative analysis of Hsp10 and Hsp90 expression in healthy mucosa and adenocarcinoma of the large bowel. Anticancer Res 34: 4153-4159, 2014.

17. Barone R, Pitruzzella A, Gammazza AM, Rappa F, Salerno M, Barone F, Sangiorgi C, D'Amico D, Locorotondo N, Di Gaudio F, et al: Nandrolone decanoate interferes with testosterone biosynthesis altering blood-testis barrier components J Cell Mol Med 21: 1636-1647, 2017.

18. Wu J, Song HF, Li SH, Guo J, Tsang K, Tumiati L, Butany J, Yau TM, Ouzounian M, Fu S, et al: Progressive aortic dilation is regulated by mir-17-associated miRNAs. J Am Coll Cardiol 678 $2965-2977,2016$

19. Ikonomidis JS, Ivey CR, Wheeler JB, Akerman AW, Rice A Patel RK, Stroud RE, Shah AA, Hughes CG, Ferrari G, et al: Plasma biomarkers for distinguishing etiologic subtypes of thoracic aortic aneurysm disease. J Thorac Cardiovasc Surg 145: $1326-1333,2013$

20. Martínez-Micaelo N, Beltrán-Debón R, Baiges I, Faiges M and Alegret JM: Specific circulating microRNA signature of bicuspid aortic valve disease. J Transl Med 15: 76, 2017.

21. Livak KJ and Schmittgen TD: Analysis of relative gene expression data using real-time quantitative PCR and the 2(-Delta Delta C(T)) method. Methods 25: 402-408, 2001

22. Agresti A (ed): Analysis of Ordinal Categorical Data. 2nd edition. Wiley, New York, NY, 2010.

23. Allison PD (ed): Logistic Regression Using SAS: Theory and Application. 2nd edition. SAS Institute Inc., Cary, NC, 2012.

24. Hosmer DW Jr and Lemeshow S: Applied Logistic Regression. 3rd edition. John Wiley \& Sons, New York, NY, 2013.

25. Baumgartner H, Falk V, Bax JJ, De Bonis M, Hamm C, Holm PJ Iung B, Lancellotti P, Lansac E, Muñoz DR, et al: ESC/EACTS Guidelines for the management of valvular heart disease. Eur Heart J 38: 2739-2791, 2017.

26. Elefteriades JA: Natural history of thoracic aortic aneurysms: Indications for surgery, and surgical versus non-surgical risks. Ann Thorac Surg 74: S1877-S1880, 2002.

27. Svensson LG and Khitin L: Aortic cross-sectional area/height ratio timing of aortic surgery in asymptomatic patients with Marfan syndrome. J Thorac Cardiovasc Surg 123: 360-361, 2002.
28. Gott VL, Greene PS, Alejo DE, Cameron DE, Naftel DC, Miller DC, Gillinov AM, Lashinger JC and Pyeritz RE: Replacement of the aortic root in patients with Marfan's syndrome. New Engl J Med 340: 1307-1313, 1999.

29. Pape LA, Tsai TT, Isselbacher EM, Oh JK, O'Gara PT, Evangelista A, Fattori R, Meinhardt G, Trimarchi S, Bossone E, et al: Aortic diameter $\geq 5.5 \mathrm{~cm}$ is not a good predictor of type A aortic dissection: Observations from the international registry of acute aortic dissection (IRAD). Circulation 116: $1120-1127,2007$

30. Etz CD, Haunschild J, Girdauskas E, Corte AD, Fedak PWM, Schäfers HJ, Sundt TM and Borger MA: Surgical management of the aorta in BAV patients. Prog Cardiovasc Dis 63: 475-481, 2020.

31. Pisano C, Maresi E, Balistreri CR, Candore G, Merlo D, Fattouch K, Bianco G and Ruvolo G: Histological and genetic studies in patients with bicuspid aortic valve and ascending aorta complications. Interact Cardiovas Thorac Surg 14: 300-306, 2012.

32. Siu SC and Silversides CK: Bicuspid aortic valve disease. J Am Coll Cardiol 55: 2789-2800, 2010.

33. Cotrufo M and Corte AD: The association of bicuspid aortic valve disease with asymmetric dilatation of the tubular ascending aorta: Identification of a definite syndrome. J Cardiovasc Med (Hagerstown) 10: 291-297, 2009.

34. Corte AD, Bancone C, Quarto C, Dialetto G, Covino FE, Scardone M, Caianello $\mathrm{G}$ and Cotrufo M: Predictors of ascending aortic dilatation with bicuspid aortic valve: A wide spectrum of disease expression. Eur J Cardiothorac Surg 31: 397-404, 2007.

35. Girdauskas E, Schulz S, Borger MA, Mierzwa M and Kuntze T: Transforming growth factor-beta receptor type II mutation in a patient with bicuspid aortic valve disease and intraoperative aortic dissection. Ann Thorac Surg 91: e70-e71, 2011.

36. Thompson RW, Holmes DR, Mertens RA, Liao S, Botney MD Mecham RP, Welgus HG and Parks WC: Production and localization of 92-kilodalton gelatinase in abdominal aortic aneurysms. An elastolytic metalloproteinase expressed by aneurysm-infiltrating macrophages. J Clin Invest 96: 318-326, 1995.

37. Longo GM, Xiong W, Greiner TC, Zhao Y, Fiotti N and Baxter BT: Matrix metalloproteinases 2 and 9 work in concert to produce aortic aneurysms. J Clin Invest 110: 625-632, 2002.

38. Tamarina NA, McMillan WD, Shively VP and Pearce WH: Expression of matrix metalloproteinases and their inhibitors in aneurysms and normal aorta. Surgery 122: 264-271, 1999.

39. Fedak PW, de Sa MP, Verma S, Nili N, Kazemian P, Butany J, Strauss BH, Weisel RD and David TE: Vascular matrix remodeling in patients with bicuspid aortic valve malformations: Implications for aortic dilatation. J Thorac Cardiovasc Surg 126: 797-806, 2003.

40. Oury C, Servais L, Bouznad N, Hego A, Nchimi A and Lancellotti P: MicroRNAs in valvular heart diseases: Potential role as markers and actors of valvular and cardiac remodeling. Int J Mol Sci 17: 1120, 2016.

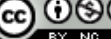

This work is licensed under a Creative Commons Attribution-NonCommercial-NoDerivatives 4.0 International (CC BY-NC-ND 4.0) License. 